\title{
An acoustic emission study of plastic deformation in polycrystalline aluminium
}

\author{
R.C. B ILL \\ Lewis Research Center, Cleveland, Ohio, USA \\ J. R. FREDERICK, D. K.FELBECK \\ Department of Mechanical Engineering, University of Michigan, Ann Arbor, Michigan, USA
}

\begin{abstract}
Acoustic emission experiments were performed on polycrystalline and single crystal 99.99\% aluminium while undergoing tensile deformation. It was found that acoustic emission counts as a function of grain size showed a maximum value at a particular grain size. Furthermore, the slip area associated with this particular grain size corresponded to the threshold level of detectability of single dislocation slip events. The rate of decline in acoustic emission activity as grain size is increased beyond the peak value suggests that grain boundary associated dislocation sources are giving rise to the bulk of the detected acoustic emissions.
\end{abstract}

\section{Introduction}

Acoustic emission is the class of phenomena whereby transient elastic waves are generated by the rapid release of energy from a localized source or sources within a material. Such a release of energy may be caused by sudden dislocation motion, crack propagation, or any microscopically unstable deformation mechanism. A wide range of materials - wood, polymers, metals, ionic crystals - are observed to show some sort of acoustic emission behaviour while under an applied stress. The magnitude of the emissions ranges from the audible sounds given off by tin when it twins, to "sounds" of minute intensity that must be amplified many thousands of times in order to be detected. The stress waves emitted by most metals during yielding are of very small amplitude, but they can be detected by amplifying the output from a piezoelectric crystal held in contact with the metal while it deforms.

For general yielding to occur throughout a polycrystalline metal, plastic deformation must be able to propagate across the grain boundaries. Li [1] envisages this to occur by the activation of Frank-Read type dislocation sources near the grain boundaries. The stress required to activate these sources may be attained with the help of dislocation pile-ups in adjacent grains.

(6) 1979 Chapman and Hall Ltd. Printed in Great Britain.
Previous acoustic emission studies [2-4] suggest that the inherent instability associated with the activation of a Frank-Read source may, under certain circumstances, render it detectable by the acoustic emission technique. There is also the possibility that dislocation unpinning may produce detectable emissions [5].

In this paper acoustic emission data relating to the microslip mechanisms that mark the onset of yield in polycrystalline aluminium are presented. In particular, evidence concerning the role of grain boundaries as slip barriers and as souces of slip is presented.

\section{Materials}

The aluminium used in this investigation was of 99.99\% purity, and had the composition shown in Table I. The processes employed to obtain the desired grain sizes are summarized in Table II. Note that all of the processes started with one of

TAB LE I Composition of $99.99 \%$ aluminium

\begin{tabular}{ll}
\hline Element & \% Composition \\
\hline Copper & 0.003 \\
Iron & 0.004 \\
Silicon & 0.001 \\
Vanadium & 0.001 \\
Zinc & 0.001 \\
\hline
\end{tabular}


T A B LE II Results of grain growth processes for $99.99 \%$ aluminium

\begin{tabular}{|c|c|c|}
\hline Original treatment & Further treatment & $\begin{array}{l}\text { Average grain } \\
\text { size }(\mu \mathrm{m})\end{array}$ \\
\hline $\begin{array}{l}20 \% \text { cold rolled } \\
3 \mathrm{~h} \text { at } 350^{\circ} \mathrm{C}\end{array}$ & & 350 \\
\hline $\begin{array}{l}20 \% \text { cold rolled } \\
3 \mathrm{~h} \text { at } 350^{\circ} \mathrm{C}\end{array}$ & $\begin{array}{l}1 \text { to } 2 \% \text { elongation } \\
1 \frac{1}{2} \text { h at } 400^{\circ} \mathrm{C}\end{array}$ & $100-200$ \\
\hline $\begin{array}{l}20 \% \text { cold rolled } \\
2 \mathrm{~h} \text { at } 250^{\circ} \mathrm{C}\end{array}$ & & $\begin{array}{l}20 \text { (sub- } \\
\quad \text { grains) }\end{array}$ \\
\hline $\begin{array}{l}20 \% \text { cold rolled } \\
2 \mathrm{~h} \text { at } 250^{\circ} \mathrm{C}\end{array}$ & $\begin{array}{l}0.3 \% \text { elongation } \\
3 \mathrm{~h} \text { at } 400^{\circ} \mathrm{C}\end{array}$ & $200-300$ \\
\hline $\begin{array}{l}20 \% \text { cold rolled } \\
2 \mathrm{~h} \text { at } 250^{\circ} \mathrm{C}\end{array}$ & $\begin{array}{l}0.3 \% \text { elongation } \\
24 \mathrm{~h} \text { at } 620^{\circ} \mathrm{C}\end{array}$ & $700-800$ \\
\hline $\begin{array}{l}80 \% \text { cold rolled } \\
3 \mathrm{~h} \text { at } 350^{\circ} \mathrm{C}\end{array}$ & & 650 \\
\hline $\begin{array}{l}80 \% \text { cold rolled } \\
3 \mathrm{~h} \text { at } 350^{\circ} \mathrm{C}\end{array}$ & $\begin{array}{l}1 \text { to } 2 \% \text { elongation } \\
24 \mathrm{~h} \text { at } 620^{\circ} \mathrm{C}\end{array}$ & $500-1000$ \\
\hline $\begin{array}{l}80 \% \text { cold rolled } \\
2 \mathrm{~h} \text { at } 250^{\circ} \mathrm{C}\end{array}$ & & $\begin{array}{l}5-10 \text { (sub- } \\
\text { grains) }\end{array}$ \\
\hline $\begin{array}{l}80 \% \text { cold rolled } \\
2 \mathrm{~h} \text { at } 250^{\circ} \mathrm{C}\end{array}$ & $\begin{array}{l}0.3 \% \text { elongation } \\
10 \mathrm{~h} \text { at } 400^{\circ} \mathrm{C}\end{array}$ & $300-400$ \\
\hline $\begin{array}{l}80 \% \text { cold rolled } \\
2 \mathrm{~h} \text { at } 250^{\circ} \mathrm{C}\end{array}$ & $\begin{array}{l}0.3 \% \text { elongation } \\
16 \mathrm{~h} \text { at } 400^{\circ} \mathrm{C}\end{array}$ & $400-500$ \\
\hline $\begin{array}{l}80 \% \text { cold rolled } \\
2 \mathrm{~h} \text { at } 250^{\circ} \mathrm{C}\end{array}$ & $\begin{array}{l}0.3 \% \text { elongation } \\
1 \frac{1}{2} \mathrm{~h} \text { at } 400^{\circ} \mathrm{C}\end{array}$ & $100-200$ \\
\hline
\end{tabular}

four original treatments. These treatments were suggested by grain refinement work on aluminium described by Perryman [6].

\section{Apparatus and procedure}

The tensile tests were conducted in a specially designed apparatus shown schematically in Fig. 1. This equipment enabled the specimens to be loaded quietly in an acoustically isolated environment. A tensile load was applied to the specimen by lowering tank $a$. The geometry of the specimen used in this investigation is shown in Fig. 2. Application of the load was such that the strain rate about $10^{-3} \mathrm{~min}^{-1}$ for all specimens.

Fig. 3 is a block diagram of the electronic equipment that was used. Normally the total amplification was set at $80 \mathrm{db}$. The bandwidth used was 120 to $180 \mathrm{kHz}$, set to match the response characteristics of the piezoelectric transducer. The trigger level setting controlled the minimum amplified signal required to register on the counter. The acoustic emission count registered on the counter was converted to a voltage by the digital to analogue converter and displayed on one axis of the $X-Y$ recorder; the other axis displayed the tensile load on the specimen. Thus a record was generated showing

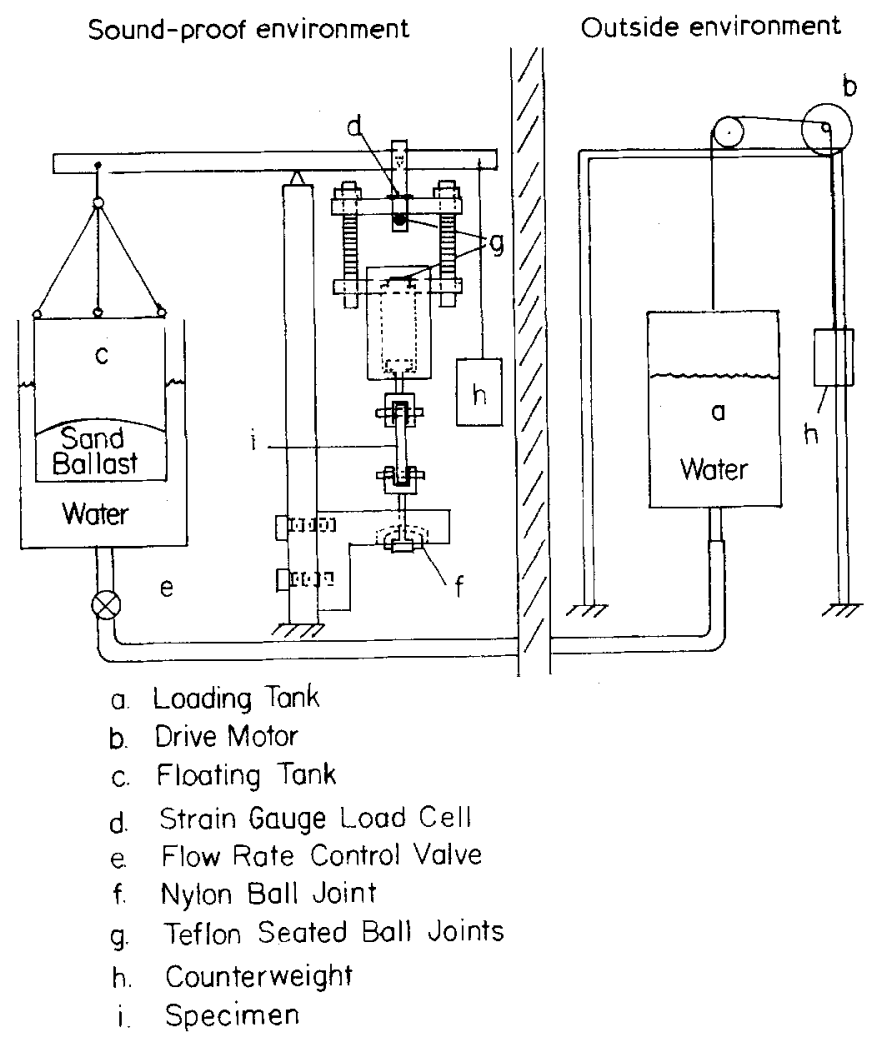

Figure 1 Diagram of the loading system. A load is applied to the test specimen (i) by lowering the water tank (a). 


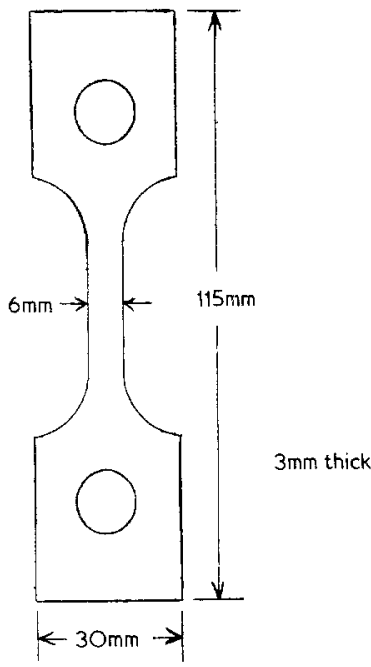

Figure 2 Tensile specimen configuration.

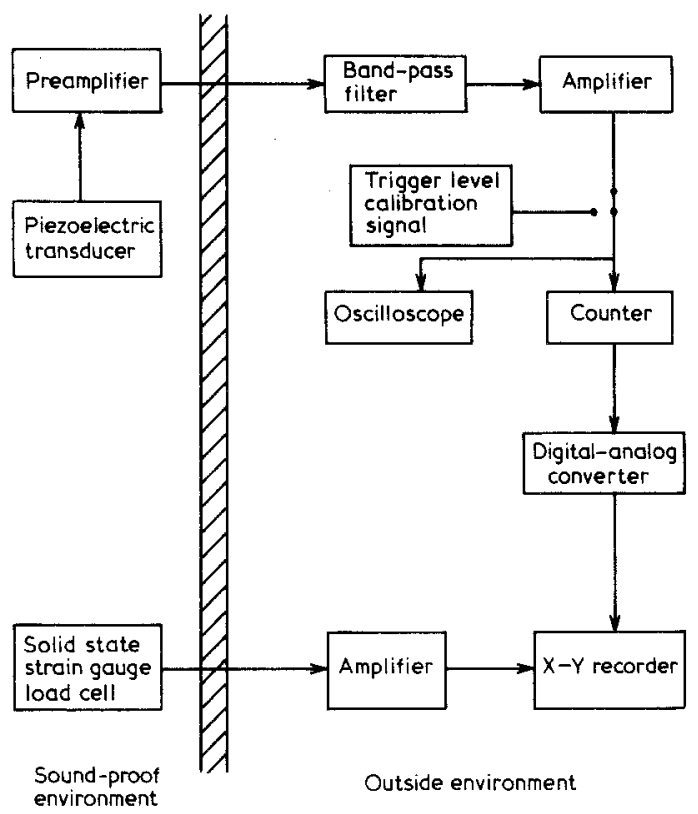

Figure 3 Block diagram of the instrumentation.

the acoustic emission count as a function of load on the specimen.

The amplified acoustic emission signal was also continuously monitored on an oscilloscope screen. Fig. 4 shows a typical acoustic emission burst from a $99.99 \% \mathrm{Al}$ specimen.

In addition to acoustic emission data, stressstrain data were obtained on the $99.99 \%$ aluminium specimens of various grain sizes. To avoid spurious acoustic emission signals emanating from the cement holding the strain gauges to the specimens, stress-strain data were taken from
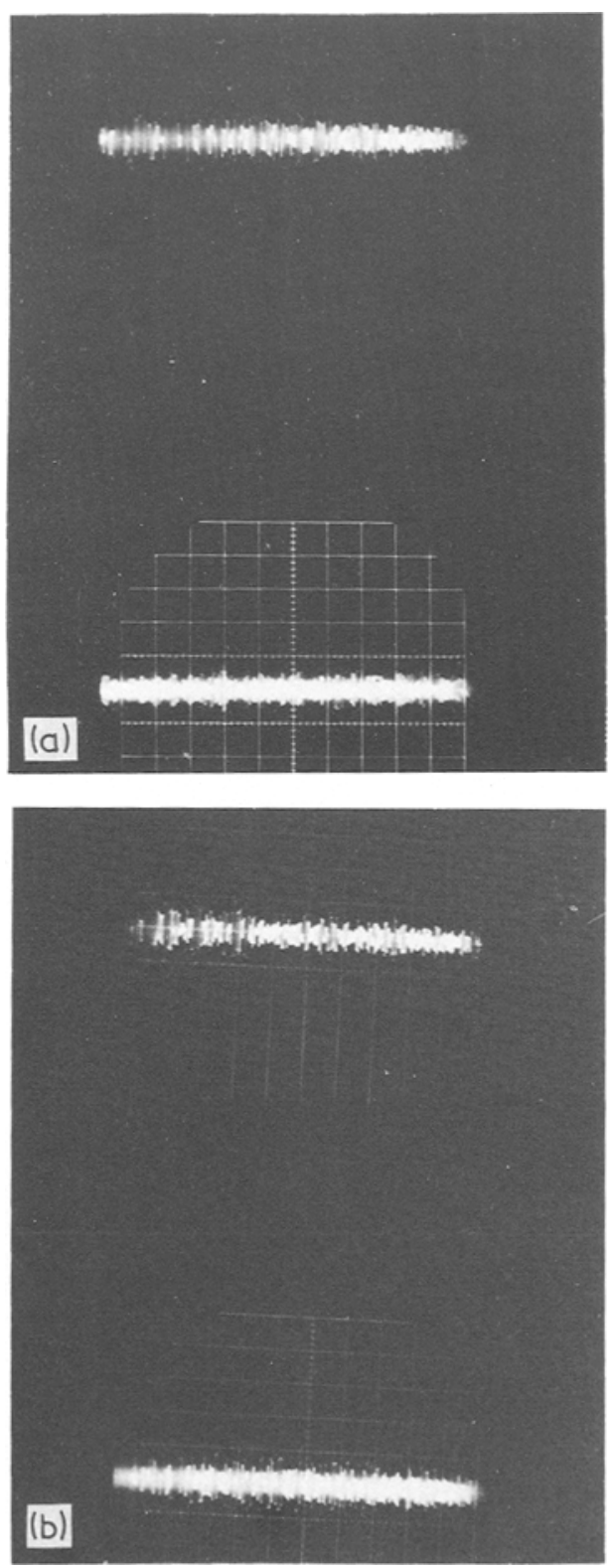

Figure 4 Oscilloscope displays of acoustic emission bursts from $99.99 \%$ aluminium. Horizontal scale is $0.1 \times 10^{-3} \mathrm{sec}$ per division; vertical scale is $0.1 \mathrm{~V}$ per division. The lower exposure of (a) shows a display of the background noise.

specimens other than those used in the acoustic emission tests.

Grain size measurements and metallographic examinations were performed on an electropolished segment of one face of each specimen gauge section. The electropolish consisted of four parts ethanol to one part perchloric acid (by volume). Grain boundaries were clearly visible 


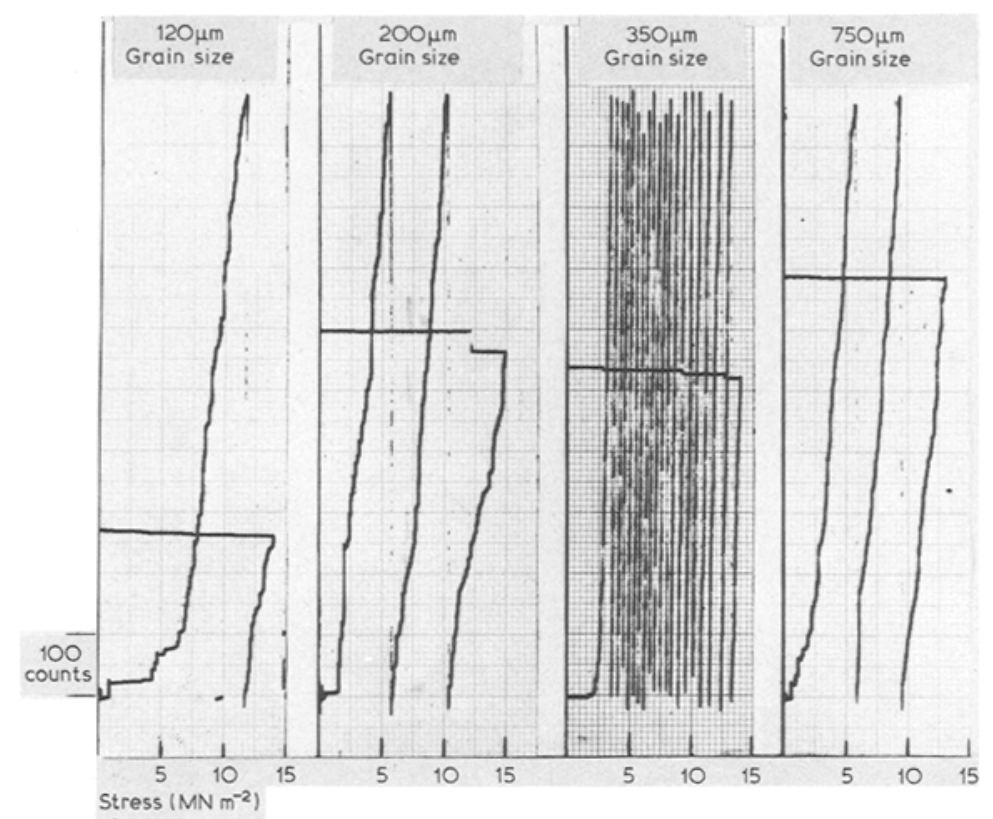

(a)

Figure 5 Chart recordings of the number of acoustic emission counts versus stress for four grain sizes. Each large square on the vertical scale is 100 counts. (a) Trigger level $0.1 \mathrm{~V}$. (b) Trigger level $0.2 \mathrm{~V}$.

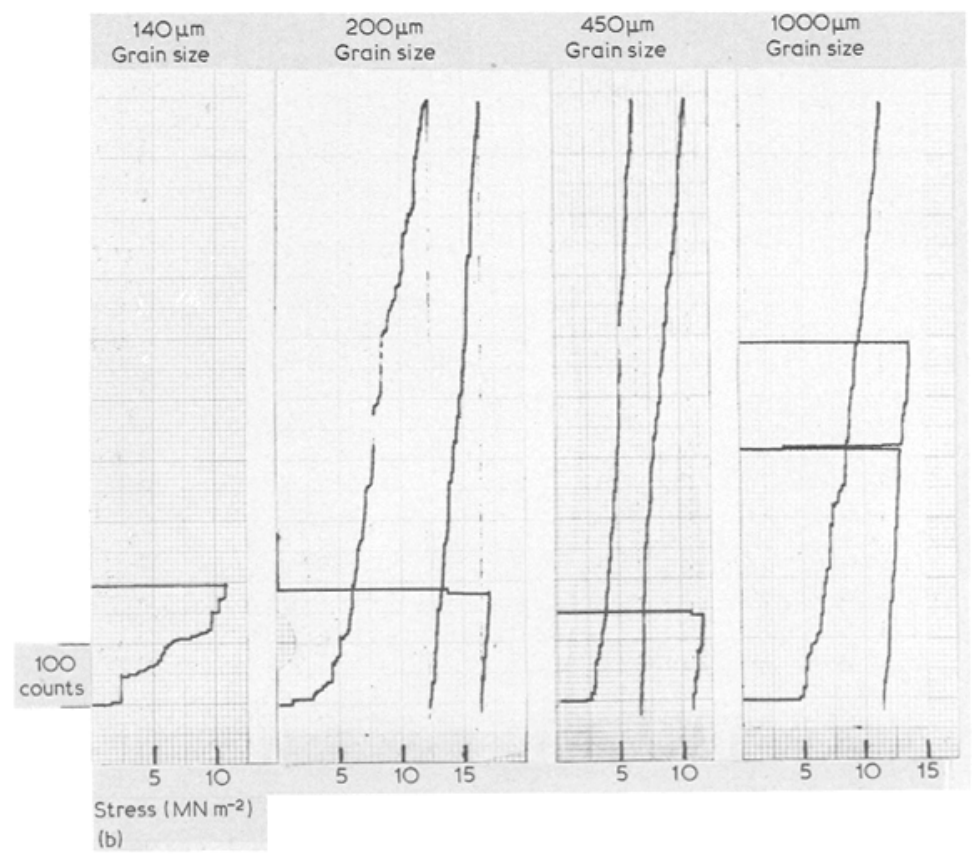

immediately after electropolishing. Grain size measurements were made from micrographs by a random line intercept method.

\section{Experimental results}

Typical curves showing the total acoustic emission counts versus stress are shown in Fig. 5a for the $0.1 \mathrm{~V}$ trigger level setting, and in Fig. $5 \mathrm{~b}$ for the $0.2 \mathrm{~V}$ trigger level setting. Two important differences between the curves for the $0.1 \mathrm{~V}$ and 28
$0.2 \mathrm{~V}$ trigger levels are noted. First is the applied stress at which acoustic emission counts begin to be registered at a high and fairly constant rate with respect to increasing stress. For grain sizes of $200 \mu \mathrm{m}$ or larger, this stress is observed to be between $1.38 \mathrm{MNm}^{-2}$ and $2.07 \mathrm{MN} \mathrm{m}^{-2}$ for a $0.1 \mathrm{~V}$ trigger level, and between $2.76 \mathrm{MN} \mathrm{m}^{-2}$ and $5.17 \mathrm{MN} \mathrm{m}^{-2}$ for a $0.2 \mathrm{~V}$ trigger level. The second difference between Figs. 5a and $b$ is in the rate with respect to stress at which the acoustic 

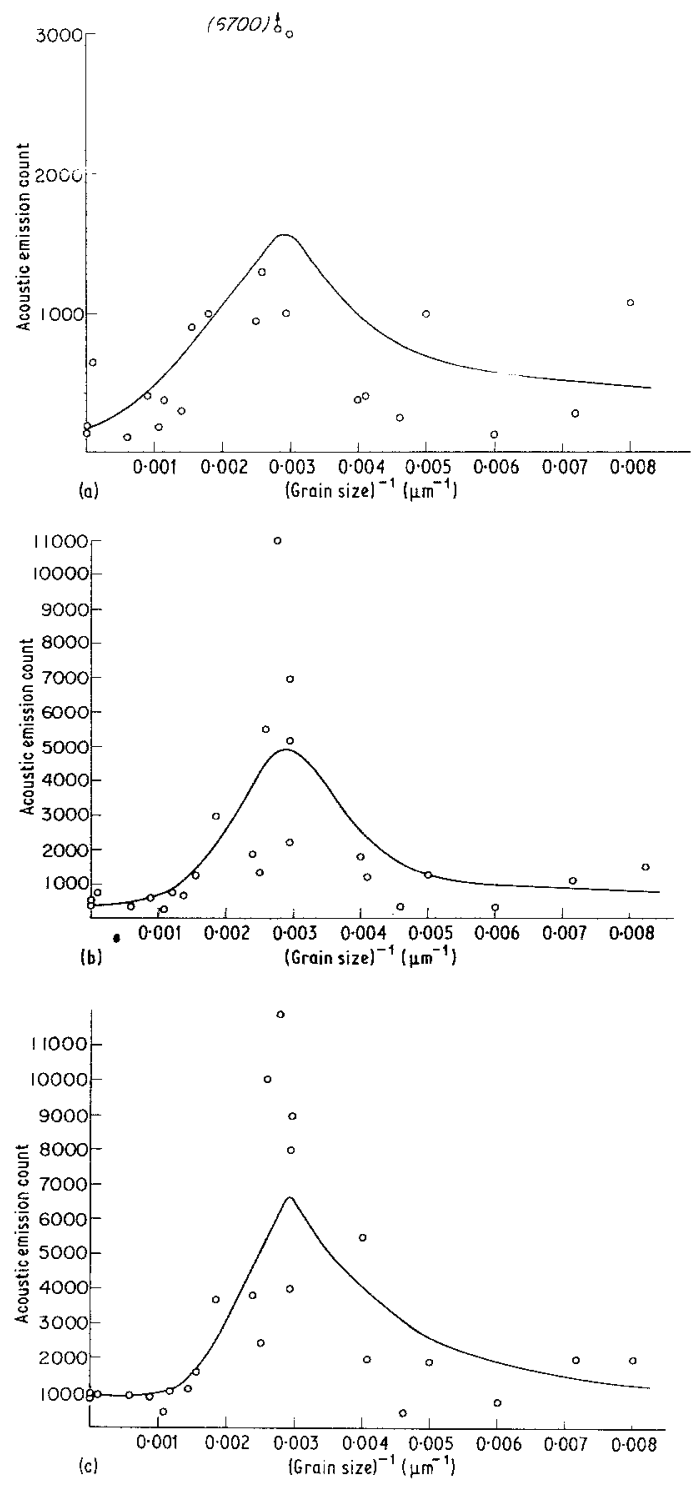

Figure 6 Acoustic emission count versus grain size curves for $99.99 \%$ aluminium, produced by a tensile stresses of (a) $6.2 \mathrm{MN} \mathrm{m}^{-2}$, (b) $8.27 \mathrm{MN} \mathrm{m}^{-2}$ and (c) $10.3 \mathrm{MN} \mathrm{m}^{-2}$. The threshold trigger level was $0.1 \mathrm{~V}$.

emission counts are registered, the rate being much higher for the $0.1 \mathrm{~V}$ trigger level.

Figs. 6 and 7 show how the acoustic emission count varies as a function of grain size at three levels of applied tensile stress for the 0.1 and $0.2 \mathrm{~V}$ trigger levels respectively. The features of interest are the presence of the peak in the curves, and the rate of decline in acoustic emission counts as a function of grain size as the grain size increases beyond the value corresponding to the position of the peak.

In Fig. 6, the peak occurs at a grain size of about $350 \mu \mathrm{m}$. For tensile stresses up to and inclu-
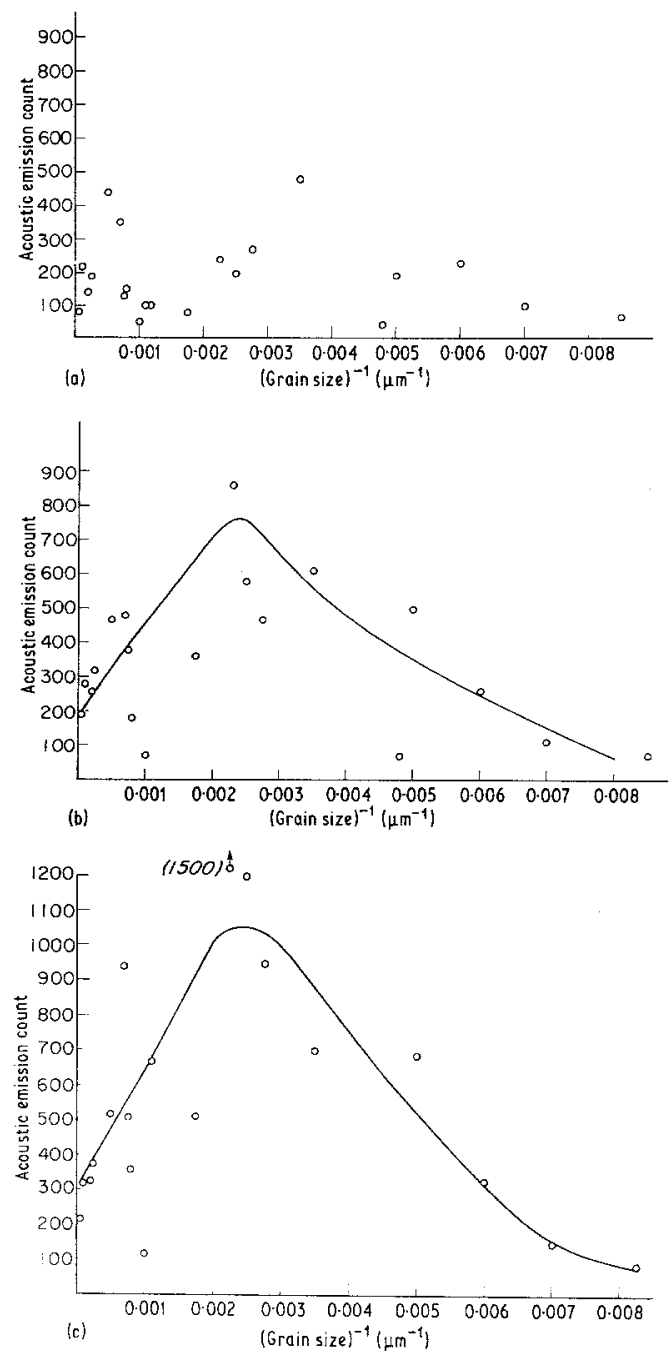

Figure 7 Acoustic emission count versus grain size curves for $99.99 \%$ aluminium, produced by tensile stresses of (a) $6.2 \mathrm{MN} \mathrm{m}^{-2}$, (b) $8.27 \mathrm{MN} \mathrm{m}^{-2}$ and (c) $10.3 \mathrm{MN} \mathrm{m}^{-2}$. The threshold trigger level was $0.2 \mathrm{~V}$.

ding $8.23 \mathrm{MN} \mathrm{m}^{-2}$ the rate of decrease in acoustic emission counts is roughly proportional to (grain size $)^{-1}$. At $10.3 \mathrm{MNm}^{-2}$ the rate of decrease seems to be steeper, and there is more scatter in the data in the vicinity of the peak.

The curves in Fig. 7 show a peak at a 400 to $450 \mu \mathrm{m}$ grain size for stresses of 8.27 and 10.3 $\mathrm{MN} \mathrm{m}^{-2}$, and the rate of decrease in acoustic emission counts is very nearly proportional to (grain size) $^{-1}$. At stresses below $8.27 \mathrm{MN} \mathrm{m}^{-2}$, it is difficult to identify the presence of a peak.

Results of the stress-strain tests are shown in Fig. 8. Once the macrostrain regime is reached, the curves do not deviate very far from linearity over the range of strain investigated. Hence, the acoustic emission count being roughly pro- 


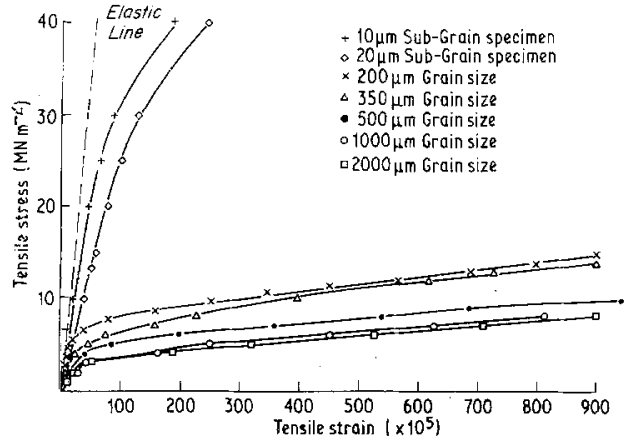

Figure 8 The effect of grain size on the stress-strain behaviour of $99.99 \%$ aluminium. portional to stress (Fig. 5) is approximately proportional to plastic strain. It appears that the major effect of grain size is to vary the stress at which the transition from microstrain to macrostrain occurs. The rate of linear hardening, at least up to $1 \%$ strain, is nearly equal for all grain sizes.

A series of examinations was made of slip line development in several tensile specimens, and is summarized in Fig. 9. Slip lines on a secondary system in the grain on the upper right are just beginning to emerge in a narrow region (encircled)
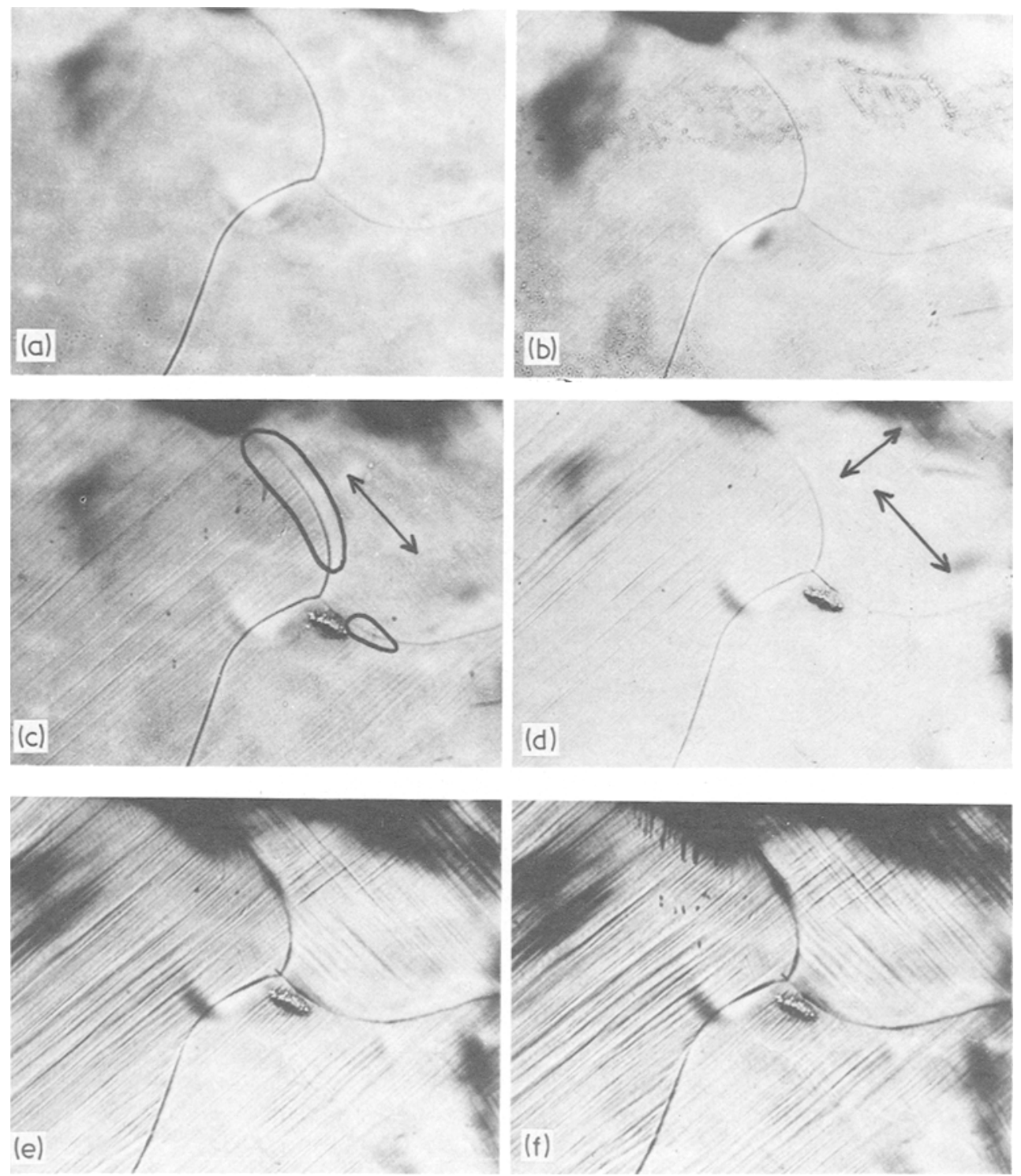

Figure 9 Slip line study of $99.99 \%$ aluminium. (a) Prior to loading, and loaded at (b) $2.07 . \mathrm{MN} \mathrm{m}^{-2}$, (c) $3.10 \mathrm{MN} \mathrm{m}^{-2}$, (d) $4.14 \mathrm{MN} \mathrm{m}^{-2}$, (e) $5.45 \mathrm{MN} \mathrm{m}^{-2}$ and (f) $6.21 \mathrm{MN} \mathrm{m}^{-2}$. Magnification $\times 48$. 
near the grain boundaries at a tensile stress of 3.10 $\mathrm{MN} \mathrm{m}^{-2}$. Two active slip planes are easily observable in the upper right grain at a $4.14 \mathrm{MNm}^{-2}$ tensile stress. Thus the stress at which acoustic emission counts begin to be registered at a high rate is not very different from the stress at which secondary slip systems may start to be activated near grain boundaries.

\section{Discussion}

Consideration will now be given to the possible mechanisms causing the observed acoustic emissions. It will be assumed that the emissions result from either a dislocation multiplication mechanism, or a dislocation unpinning mechanism. In the latter dislocations are envisioned to break away from pinning points or barriers in the grain interiors.

Regardless of which of the above two mechanisms dominates it must explain two key observations; (1) the acoustic emission count is roughly proportional to strain; (2) the proportionality factor is strongly dependent on grain size. Dislocation unpinning may be easily visualized to result in a uniform rate of emission with strain. However, initial dislocation measurements show that the $99.99 \% \mathrm{Al}$ specimen could have undergone plastic strains of not more than $0.1 \%$ to $0.2 \%$ without some dislocation multiplication occurring. In order for the multiplication events themselves not to be the major source of emission; it is necessary that dislocation blocking and unpinning occur as dislocations advance across a grain. Such a situation would necessarily mask the grain boundaries as major slip obstacles, and there would be no way for a grain size effect to emerge. Hence, it is unlikely that dislocation unpinning is the major source of emissions for polycrystalline $99.99 \% \mathrm{Al}$.

Dislocation multiplication can account for the observed uniform rate of emission with respect to stress (hence, approximately strain) if there exists an inverse distribution of Frank-Read type sources as a function of source width. This follows since

$$
\sigma_{\text {act }}=G b / f
$$

where $\sigma_{\text {act }}$ is the stress required to activate a Frank-Read source of width $f$, and $G$ is the shear modulus of the material. Thus, it may be stated that

$$
\Delta N \propto \Delta \sigma \Leftrightarrow \Delta n \propto 1 / f
$$

where $\Delta n$ is the number of sources activated by the stress increment $\Delta \sigma$, resulting in $\Delta N$ acoustic emission counts, and $f$ is the average width of those sources activated as the stress increases from $\sigma$ to $\sigma+\Delta \sigma$.

More important though, is whether or not the dislocation source activation model (2) can explain the effect that grain size has on the emission rate. Assume first that the dislocations from an activated source are able to sweep across an entire grain in a single unstable step. The increase in the observed rate of emission as the grain size increases up to the value corresponding to the position of the peak is easily understood. The larger slip area associated with the larger grain size renders a greater fraction of the activated sources detectable by the transducer.

The dislocation source activation model can also explain the decline in the rate of emission as the grain size increases beyond the peak. However, the model must first be modified. The propagation of slip across a grain boundary very likely occurs when the stress concentration at the head of a dis. location pile-up becomes sufficient to activate dislocation sources in the neighbouring grain [1]. Suppose that the dislocation sources producing the detected emissions are in fact these grain boundary breakthrough sources. This supposition is partially supported by observing in Fig. 9 that grain boundary related slip events seem to occur at stress levels similar to those marking the onset of high rate of acoustic emission. The rate of decrease in acoustic emission counts that is roughly proportional to (grain size) $^{-1}$ is now easily understood. The number of these grain boundary associated dislocation sources activated at a given stress should be proportional to the grain boundary surface area in the specimen, which in turn is proportional to (grain size) ${ }^{-1}$

The significance of the position of the peaks in Figs. 6 and 7 may now be understood by relating the surface displacement of the specimens due to the activation of a dislocation source and the sensitivity of the acoustic emission transducer. If a dislocation source emits $Z$ dislocations that are able to sweep across a slip area $a$, the displacement $\Delta x$, at the end of the specimen is

$$
\Delta x=Z b a / 2 A
$$

where $b$ is the Burgers vector $(0.286 \mathrm{~nm}$ for $a / 2\left[\begin{array}{lll}1 & 1 & 0\end{array}\right]$ in $\mathrm{Al}$ ), and $A$ is the cross-sectional area of the specimen, namely $20 \mathrm{~mm}^{2}$. The factor 2 
translates the shear displacement produced by a typical source into the resultant displacement at the specimen surface. $\Delta x$ should thus be of the order 0.1 to $1.0 \mathrm{pm}$ in order for a $0.1 \mathrm{~V}$ signal (measured at the counter) to be produced by the transducer [7]. If $Z$ is taken to be 1 , representing the smallest of the dislocation source events, then the slip area must be at least $0.1 \mathrm{~mm}^{2}$ for a $0.1 \mathrm{~V}$ signal to result. A slip area of $0.1 \mathrm{~mm}^{2}$ corresponds to a grain size of 300 to $350 \mu \mathrm{m}$, which is close to the observed position of the peak in Fig. 6. Thus the position of the peak corresponds to that grain size at which it becomes just possible to detect the smallest grain boundary sources that can propagate dislocations across an entire grain. This idea is given support by the effect that doubling the trigger level is observed to have on the position of the peak. Doubling the trigger level effectively doubles the minimum slip area required to render a dislocation source detectable. Thus, applying the arguments presented above, it would be expected that doubling the trigger level should move the peak position to a larger grain size, larger by a factor of $\sqrt{ } 2$. The position of the peak in Fig. 7, at 400 to $450 \mu \mathrm{m}$, is in fact displaced by a factor of approximately $\sqrt{ } 2$ compared to the peak position in Fig. 6 .

Some remarks may now be made about the micromechanics of yielding in $99.99 \%$ aluminium. Locally, slip across grain boundaries is initiated in a sudden, unstable manner, probably by the activation of many dislocation sources in a small region near the grain boundary. The subsequent development of strain, with the resultant for- mation of slip lines, occurs in a series of very small events that give rise to very few detectable acoustic emissions. These events might include the breaking of attractive junctions, breakaway from impurities, forest dislocation intersections, and possibly the activation of secondary dislocation sources.

\section{Conclusions}

The following conclusions can be drawn from the work that has been described:

(1) The acoustic emissions detected from polycrystalline $99.99 \%$ aluminium when subjected to a tensile stress are the result of the activation of dislocation sources.

(2) These sources are generally associated with grain boundaries, and their activation marks the onset of macrostrain $\left(\epsilon=10^{-5}\right.$ to $\left.10^{-4}\right)$.

(3) Comparatively few of the slip events that lead to the further development of slip bands are detected.

\section{References}

1. J. C. M. LI Trans. AIME 227 (1963) 239.

2. A. B. L. AGARWAL, J, R. FREDERICK and D. K. FELBECK, Met. Trans. ASM 1 (1970) 1069.

3. R. M. FISHER and J. S. LALly Canadian J. Phys. 45 (1967).

4. R. T. SEDGEWICK, J. Appl. Phys. 39 (1968).

5. D. R. JAMES, Ph.D. Thesis, University of Denver (1970).

6. E. W. C. PERRYMAN, Trans. AIME 203 (1955) 1053.

7. R. C. BILL, Ph.D. Thesis, The University of Michigan, (1970) pp. 118-22.

Received 9 January and accepted 25 April 1978. 